\title{
Ubiquitous Bugs and Drugs Education for Children Through Mobile Games
}

\author{
Andreea Molnar \\ University of Portsmouth \\ Winston Churchill Avenue \\ Portsmouth, United Kingdom \\ andreea.molnar@port.ac.uk
}

\author{
Patty Kostkova \\ University College London \\ Gower Street \\ London, United Kingdom \\ p.kostkova@ucl.ac.uk
}

\begin{abstract}
Increasing mobile device ownership among children makes them an attractive platform for raising awareness about health issues. At the same time, children are using mobile devices for playing games and therefore these games could be used to facilitate the delivery of important healthcare messages in an enjoyable manner. In this article we present edugames4all MicrobeQuest!, a mobile game that aims to create awareness among 9 to 12 years old on healthcare issues related to microbe transmission, food and hand hygiene, and responsible antibiotic use. This article discusses the preliminary research performed in assessing the usability of the game.
\end{abstract}

\section{Categories and Subject Descriptors}

H.4 [Information Systems Applications]: Miscellaneous; I.1.1 [Applications and Expert Systems]: Games; K.8 [Personal Computing]: Games; J.3 [Life and Medical Sciences]: Health

\section{Keywords}

mobile apps, games, serious games, games for health, educational games, children, health, usability

\section{INTRODUCTION}

Edugames4all MicrobeQuest! [10] was developed as a mobile version (app) of the e-bug and later on edugames4all platform games [8]. Edugames4all is a collection of educational games that aim to raise awareness about important healthcare issues among children. It consists of several platform [5] and interactive storytelling based games [7]. The game's educational content focuses on core concepts of the European curriculum and were developed in collaboration with experts in healthcare and education [5].

Originally edugames4all contained games that were aimed at being played on computers. However, due to the increased ownership of mobile devices among children [1], mobile devices became an attractive platform for educational inter-

Permission to make digital or hard copies of part or all of this work for personal or classroom use is granted without fee provided that copies are not made or distributed for profit or commercial advantage and that copies bear this notice and the full citation on the first page. Copyrights for third-party components of this work must be honored. For all other uses, contact the owner/author(s).

DH '16 April 11-13, 2016, Montréal, QC, Canada

Q2016 Copyright held by the owner/author(s).

ACM ISBN 978-1-4503-4224-7/16/04

DOI: http://dx.doi.org/10.1145/2896338.2896366 ventions. As a result, to reach a higher number of children, a mobile version of a selection of the edugames4all games was implemented called edugames4all MicrobeQuest! [10].

Edugames4all MicrobeQuest! is aimed at creating awareness about microbe transmission, food and hand hygiene and responsible antibiotic use among children with ages of 9 to 12 years old. The game is organised across different missions, starting with a tutorial mission aiming to familiarise the player with the game mechanics. The game missions facilitate the exploration of different environments such as: human hand, human body or the food in the kitchen. During these explorations, the player is taught the learning objectives through game mechanics and text incorporated into the game. Whenever possible, the learning objective were reinforced in more than one of the missions.

Although the desktop version of this game has been previously evaluated [5], the mobile version has not been. This article presents the results of the usability of the edugames4all MicrobeQuest!. The next section briefly introduces the research performed on educational mobile games. This paper continues with the usability evaluation of the game and the discussion of the results. The article ends with our conclusions and future work.

\section{MOBILE GAMES FOR HEALTH}

Mobile devices have been used to facilitate the usage of serious games with various aims, such as improving medication compliance for elders [3], promote healthy eating among adults [6], or promoting physical activity among various age groups [12]. Positive results have been reported in the research literature for medication compliance, an improvement that has been higher for participants that had an existing interest in games [3]. Players of OrderUP! [6], a game that aims to improve understanding of healthy eating, have shown early engagement changing their eating habits [6].

As opposed to the above games, our game focuses on creating awareness about hygiene and responsible antibiotic use among children. Hand hygiene significantly reduces illness related absences [11], whereas antibiotic resistance is an ongoing concern and responsible antibiotic use could help alleviate this issue [4].

\section{USABILITY EVALUATION}

To evaluate the usability we used mixed methods by combining System Usability Scale (SUS) [2] with observations. The original SUS questionnaire [2] was modified so that the wording is suitable for our participants age group and 
adapted towards game usability evaluation by changing the word "system" to "game" and "use" with "play" as in [9]. SUS questionnaire is a way of quantifying the usability of the game, however it does not show where the problem is. As a result, observations during the study were used deter- mine whether there are issues, if any.

A total of 15 participants from two primary schools took part in the study on a voluntary basis. They came from different socio-economic backgrounds and their average age was 10 years old. A total of eight participants are girls and seven are boys. All the participants reported playing games for entertainment purposes.

The participants were given a mobile phone (Samsung Galaxy S4), which had the game already pre-installed. They were asked to play the game for thirty minutes. Afterwards they were asked to fill a questionnaire which comprises of demographic data (age, gender), previous playing experience and the SUS questionnaire. A short discussion followed, during which the researcher discussed the issues observed during the game playing session with the children to clarify eventual misunderstanding.

The SUS score of the game was 61, which is considered "OK". Overall all the children enjoyed playing the game and were eager to play it again. There were also some difficulties

noticed during the game play. First, it was observed that not all the children managed to advance to the next level as the students find it difficult to execute one of the game mechanics (i.e. a jump) that would have allowed them to continue with the game. Those who actually did, found it easier to progress to the next levels. The difficulty in passing that level happened regardless of the player's previous experience with playing games. We also found that the mobile version of the game was "too slow" for some of the children.

These issues have not been noticed in our previous usability evaluations of the desktop version of the game, although we have noticed a big drop in the number of players after

the first level [5]. Further research is needed to investigate whether this was the reason behind it. Difficulty of executing some game mechanics might be due to the fact that they are more difficult to execute on the mobile version of the game, as opposed to the desktop version of the game. The game was being perceived as too slow and the slowness might be caused by two issues: (a) the mobile phone used in the study was not performant enough to support the graphics the game has or (b) the children actually expect a faster response time from the mobile game than from a desktop game.

\section{CONCLUSIONS AND FUTURE WORK}

We presented edugames4all MicrobeQuest!, a mobile game app aimed at teaching children microbiology. We have evaluated the usability of the game and we have discussed some of the difficulties encountered in the study.

Our future work will focus on exploring whether theinteractions observed through the mobile game are due to differences in children expectations among two different mediums of communication and difficulties in executing certain actions on mobile phones as opposed to desktops. We also want to compare how children interactions and enjoyment differs when the children play the mobile version of the game as opposed to a desktop version of the game [10]. We are also planning to compare the children learning performance and their enjoyment when playing the desktop version of the game to the the mobile version.

\section{ACKNOWLEDGMENTS}

Our thanks go to Fariz Benchaoui, Charlie Green and Jonny Wildey for developing the mobile app; the school teachers that have facilitated the study, the children who have taken part in the study and to DG SANCO for fund- ing the e-Bug project. This research was partially supported by the University of Portsmouth Research Accelerator Fund.

\section{REFERENCES}

[1] One in Three Children has their own Tablet Computer, 2014. [Online; accessed 29-January-2015].

[2] J. Brooke. Sus-a quick and dirty usability scale. Usability Evaluation in Industry, 189(194):4-7, 1996.

[3] R. De Oliveira, M. Cherubini, and N. Oliver. Movipill: improving medication compliance for elders using a mobile persuasive social game. In Proceedings of the 12th ACM International Conference on Ubiquitous Computing, pages 251-260. ACM, 2010.

[4] J. Fahrenkamp-Uppenbrink. Countering antibiotic resistance. Science, 347(6226):1109-1111, 2015.

[5] D. Farrell, P. Kostkova, J. Weinberg, L. Lazareck, D. Weerasinghe, D. M. Lecky, and C. A. McNulty. Computer games to teach hygiene: An evaluation of the e-bug junior game. Journal of Antimicrobial Chemotherapy, 66(suppl 5):v39-v44, 2011.

[6] A. Grimes, V. Kantroo, and R. E. Grinter. Let's play!: mobile health games for adults. In Proceedings of the 12th ACM international conference on Ubiquitous computing, pages 241-250. ACM, 2010.

[7] A. Molnar and P. Kostkova. If you build it would they play? challenges and solutions in adopting health games for children. In Proceedings of ACM SIGCHI Conference on Human Factors in Computing Systems, Let?s talk about Failures: Why was the Game for Children not a Success, 2013.

[8] A. Molnar and P. Kostkova. On effective integration of educational content in serious games: Text vs. game mechanics. In IEEE 13th International Conference on Advanced Learning Technologies, pages 299-303. IEEE, 2013.

[9] A. Molnar and P. Kostkova. Gaming to master the game: Game usability and game mechanics. In IEEE International Conference on Serious Games and Applications for Health. IEEE, May 2014.

[10] A. Molnar and P. Kostkova. Mind the gap: From desktop to app. In Proceedings of the 5th International Conference on Digital Health 2015, pages 15-16. ACM, 2015.

[11] I. Nandrup-Bus. Mandatory handwashing in elementary schools reduces absenteeism due to infectious illness among pupils: a pilot intervention study. American journal of infection control, 37(10):820-826, 2009.

[12] M. Tabak, M. Dekker-van Weering, H. van Dijk, and M. Vollenbroek-Hutten. Promoting daily physical activity by means of mobile gaming: a review of the state of the art. Games for Health Journal, 4(6):460469, 2015. 